\title{
Enhanced recovery after surgery (ERAS) versus conventional postoperative care in patients undergoing abdominal hysterectomies
}

\author{
Gulseren Yilmaz ${ }^{1}$, Aysu Akca ${ }^{2}$, Nevin Aydin ${ }^{1}$ \\ ${ }^{1}$ Department of Anesthesiology \& Reanimation, University of Health Sciences, Faculty of Medicine, \\ Kanuni Sultan Suleyman Hospital, Istanbul, Turkey \\ ${ }^{2}$ Department of Obstetrics and Gynecology, University of Health Sciences, Faculty of Medicine, \\ Kanuni Sultan Suleyman Hospital, Istanbul, Turkey
}

\begin{abstract}
Objectives: In the present study, we aimed to compare the postoperative compliance and complications between ERAS and conventional postoperative care in patients undergoing abdominal hysterectomies.

Material and methods: This is the prospective, randomized, controlled trial, which involved 62 patients, who underwent abdominal hysterectomy between December 2016 to February 2017. A total of 30 patients formed the ERAS group. A total of 32 patients who received conventional perioperative care and matched for age, body mass index (BMI) and American Society of Anesthesiologists score were assigned as a control group. Groups were compared in terms of patient characteristics [age, body mass index, ASA Score, parity, diagnosis, type of surgery, and perioperative intravenous fluids], postoperative compliance (postoperative intravenous fluids, time to first flatus, first defecation, ambulation, eating solid food, and postoperative hospital stay), and postoperative complications.

Results: Peri- and post-operative administrated intravenous fluids were significantly lower in the ERAS group ( $p<0.001$ for both). Time to first flatus ( $p=0.001)$, time to first defecation $(p<0.001)$, and time to eating solid food ( $<<0.001)$ were all significantly shorter in the ERAS group. Post-operative early mobilization on the first postoperative day was achieved in eight (26.7\%) patients in the ERAS group. There were no significant differences in complications. One (3.3\%) patient in the ERAS Group and 11 (34.4\%) patients in the Conventional Group required hospital readmission after discharge ( $p=0.002)$.

Conclusion: The ERAS protocol seems to be a simple tool for reducing the incidence of postoperative complications and shortening hospitalization.
\end{abstract}

Key words: Enhanced recovery after surgery, ERAS, abdominal hysterectomy

\section{INTRODUCTION}

As it is known, current treatment, and health care, and evidence based applications may speed up postoperative recovery, and decrease surgery-related deaths [1,2]. One of the evidence-based applications which emerge in line with this thought, is "Enhanced Recovery After Surgery" (ERAS) protocol developed by ERAS Society [1]. ERAS protocol may be described as, "to standardize surgical process by preventing surgery-related trauma which discloses psychologic problems, and organ dysfunctions during surgery, and to provide the most possible treatment, and health care with resultant discharge of the patient as soon as possible" [2]. ERAS protocol is a composition of evidence-based findings which contains recommendations about patient care at different phases of operative process and requires a multidisciplinary approach practiced with professionals working in synergy so as to shorten postoperative recovery period of the patient $[3,4]$. Main purpose of the protocol is to decrease reactions of the patients to operative stress, postoperative morbidity, and mortality, hospital stay, and favorably effect 
patients' perceptions about surgery. Besides, ERAS protocol targets to minimize pain, complication, and dysfunctions of the organ systems which may occur after discharge [2, 5]. ERAS protocol was firstly applied in 1997 in colorectal surgery, and successful results were obtained [6].

Hysterectomy is one of the utmost frequent major gynecological surgeries. Even though, less invasive approaches such as laparoscopic or vaginal procedures are suggested primarily, the standard procedure for most cases is abdominal hysterectomy $[7,8]$. The major causes for counselling vaginal or laparoscopic hysterectomy over the abdominal method is earlier beginning of routine actions, shorter hospital stay, fewer bleeding, and fewer infections. On the other hand, these advantages might be at the expense of further injuries of the urinary tract and extended surgery time for laparoscopic approaches [8].

Møller et al. challenged the benefit of laparoscopic vs. abdominal hysterectomy by introducing a fast track setting for benign hysterectomy [9]. ERAS for major gynecological surgery have been more recently presented in controlled studies, but up to now, individual reports have been published [10-13].

In the present study, we aimed to compare the postoperative compliance and complications between ERAS and conventional postoperative care in patients undergoing abdominal hysterectomies.

\section{MATERIAL AND METHODS Study design}

The study has been conducted in accordance with the principles of the Helsinki Declaration and approved by the local Institutional Review Board (KAEK/2016.12.12). Written informed consent was obtained from all subjects.

This is the prospective, randomized, controlled study, which involved 62 patients, who underwent abdominal hysterectomy between December 2016 and February 2017. A total of 30 patients formed the ERAS group. A total of 32 patients who received conventional perioperative care and matched for age, body mass index (BMI) and American Society of Anesthesiologists (ASA) score were assigned as a control group.

\section{Conventional care}

Patients were admitted the day before their operation. In the operating room all patients received a urinary catheter. Thirty minutes before the first incision, cefoperazone (1000 mg) was given intravenously. Patients were operated under general anesthesia. Postoperatively, oral intake was prohibited, and standard intravenous fluid was set at 2-2.5 L/24 h. Patients received $4000 \mathrm{mg}$ of paracetamol (in four separate doses of $1000 \mathrm{mg}$ ). If necessary, diclofenac $150 \mathrm{mg}$ in three doses of $50 \mathrm{mg}$ and morphine substitutes were also given. Discharge was arranged when the following criteria were met: there are no remaining lines or catheters, solid food is tolerated, there has been the passage of stool, pain is controlled using oral analgesics only and the patient is able to restart basic daily activities and self-care.

\section{Early Rehabilitation After Surgery Protocol}

The components of ERAS multidisciplinary pathway concerning preoperative, operative, and postoperative period are shown in Table 1.

\section{Outcome parameters}

Groups were compared in terms of patient characteristics [age, body mass index (BMI), ASA Score, parity, diagnosis, type of surgery, and perioperative intravenous fluids], postoperative compliance (postoperative intravenous fluids, time to first flatus, first defecation, ambulation, eating solid food, and postoperative hospital stay), and postoperative complications.

\section{Statistical analysis}

All collected data were entered into a database and analyzed using SPSS Statistics 17.0 for Windows. To determine significant differences between the ERAS and control

\begin{tabular}{|c|c|}
\hline \multirow{6}{*}{ Preoperative } & Fluid and carbohydrate Ioadina \\
\hline & Avoiding prolongation of fasting period \\
\hline & $\begin{array}{l}\text { Avoiding bowel preparation or its application } \\
\text { only in selective cases }\end{array}$ \\
\hline & Application of antibiotic prophylaxis \\
\hline & Application of thromboprophylaxis \\
\hline & Avoiding premedication \\
\hline \multirow{5}{*}{ Perioperative } & Use of short-acting anesthetic agents \\
\hline & $\begin{array}{l}\text { Application of midthoracal, epidural } \\
\text { anesthesia/analgesia }\end{array}$ \\
\hline & Refraining from using drains \\
\hline & Refraining from salt, and water overload \\
\hline & $\begin{array}{l}\text { Maintenance of normothermia (heating the body, } \\
\text { and use of warmed up intravenous fluids) }\end{array}$ \\
\hline \multirow{9}{*}{ Postoperative } & $\begin{array}{l}\text { Application of midthoracal, epidural } \\
\text { anesthesia/analgesia }\end{array}$ \\
\hline & Refraining from use of nasogastric tube \\
\hline & Prevention of nausea, and vomiting \\
\hline & Refraining from salt, and water overload \\
\hline & Earlier removal of catheters \\
\hline & Initiation of oral intake at an early period \\
\hline & Use of nonopioid oral analgesics/NSAIDs \\
\hline & Early mobilization \\
\hline & Adherence to the protocol, and auditing results \\
\hline
\end{tabular}


groups, statistical analysis was performed using a $X^{2}$ test. A P-value $<0.05$ was considered statistically significant. Continuous data are expressed as median (range) or as mean ( $\pm S D$ ) and were analyzed using Mann-Whitney $U$ test. BMI was converted to a categorical variable, representing certain risk groups. All categorical and dichotomous variables were analyzed using $X^{2}$ test.

\section{RESULTS}

ERAS Group included 30 patients with a mean age of $47.9 \pm 7.36$ years and Conventional Group included 32 patients with a mean age of $48.3 \pm 5.84$ years. No significant differences in patient demographics between the two groups were found. Both groups did not differ from each other by means of age $(p=0.806), B M I(p=0.528)$, and ASA score $(p=0.688)$. There were no significant differences between the groups regarding diagnosis $(p=0.429)$, and type of surgery $(p=0.429)($ Tab. 2$)$.
Peri- and post-operative administrated intravenous fluids were significantly lower in the ERAS group $(p<0.001$ for both). Time to first flatus $(p=0.001)$, time to first defecation $(p<0.001)$, and time to eating solid food $(p<0.001)$ were all significantly shorter in the ERAS group. Post-operative early mobilization on the first postoperative day was achieved in eight (26.7\%) patients in the ERAS group. On the other hand, none of the control group patients mobilized on day 1. ERAS protocol led to a significantly shorter length of hospital stay $(p=0.010)$ (Tab. 3).

There were no significant differences in complications (Tab. 4). The types of complications are listed in Table 4. A total of $9(30 \%)$ patients in the ERAS Group and 12 (37.5\%) patients in the Conventional Group suffered from a complication ( $p=0.112$ ) such as vaginitis, wound infection, chest pain, abdominal pain, perioperative bleeding, and sub-ileus. One (3.3\%) patient in the ERAS Group and 11 (34.4\%)

Table 2. Characteristics of the study group, diagnosis and perioperative data

\begin{tabular}{|c|c|c|c|c|c|}
\hline \multicolumn{3}{|c|}{ Patient characteristics } & $\begin{array}{l}\text { ERAS care } \\
(n=30)\end{array}$ & $\begin{array}{l}\text { Conventional care } \\
\qquad(n=32)\end{array}$ & p Value \\
\hline \multicolumn{3}{|l|}{ Age (years) } & $47.9 \pm 7.36$ & $48.3 \pm 5.84$ & 0.806 \\
\hline \multicolumn{3}{|l|}{ BMI $\left(\mathrm{kg} / \mathrm{m}^{2}\right)$} & $29.69 \pm 5.01$ & $30.55 \pm 5.55$ & 0.528 \\
\hline \multirow{3}{*}{\multicolumn{2}{|c|}{ ASA Score }} & 1 & $4(13.3 \%)$ & $5(15.6 \%)$ & \multirow{3}{*}{0.688} \\
\hline & & 2 & $21(70 \%)$ & $24(75 \%)$ & \\
\hline & & 3 & $5(16.7 \%)$ & $3(9.4 \%)$ & \\
\hline \multirow{3}{*}{ Diagnosis } & \multicolumn{2}{|c|}{ Myoma } & $24(80 \%)$ & $29(90.6$ & \multirow{3}{*}{0.429} \\
\hline & \multicolumn{2}{|c|}{ Abnormal uterine bleeding } & $5(16.7 \%)$ & $2(6.3 \%)$ & \\
\hline & \multicolumn{2}{|c|}{ Endometriosis } & $1(3.3 \%)$ & $1(3.1 \%)$ & \\
\hline \multirow{2}{*}{ Surgery } & $\mathrm{HSOE}$ & & $18(60 \%)$ & $16(50 \%)$ & \multirow{2}{*}{0.429} \\
\hline & HS & & $12(40 \%)$ & $16(50 \%)$ & \\
\hline \multicolumn{3}{|c|}{ Perioperative intravenous fluids $(\mathrm{mL})$} & $1200(100)$ & 1775 (475) & $<0.001$ \\
\hline
\end{tabular}

ERAS - enhanced recovery after surgery; BMI — body mass index; HSOE — hysterectomy and salpingo-oophorectomy; HS — hysterectomy and salpingectomy. Data are expressed as median (range) or as mean \pm SD

Table 3. Postoperative compliance/outcome

\begin{tabular}{|l|c|c|c|}
\hline Patient characteristics & \multicolumn{1}{c|}{$\begin{array}{c}\text { ERAS care } \\
\text { (n=30) }\end{array}$} & $\begin{array}{c}\text { Conventional care } \\
\text { (n=32) }\end{array}$ & $16.4 \pm 5.88$ \\
\hline Time to first flatus (hours) & & $11.7 \pm 4.45$ & 0.001 \\
\hline Time to first defecation (hours) & Day 1 & $24.9 \pm 5.73$ & $37.2 \pm 10.25$ \\
\hline & Day 2 & $8(26.7 \%)$ & 0 \\
\hline Time to ambulation (days) & Day 3 & $19(63.3 \%)$ & $26(81.3 \%)$ \\
\hline Time to eating solid food (days) & & $3(10.0 \%)$ & $6(18.8 \%)$ \\
\hline Postoperative intravenous fluids (first 3 days) $(\mathrm{mL})$ & $1.5(1.00)$ & $2.0(1.00)$ \\
\hline Postoperative hospital stay (days) & $1250(1000)$ & $3000(0)$ \\
\hline
\end{tabular}

ERAS - Enhanced Recovery After Surgery; data are expressed as median (range) or as mean \pm SD 
Table 4. Postoperative complications

\begin{tabular}{|l|c|c|c|}
\hline Patient characteristics & $\begin{array}{c}\text { ERAS care } \\
(\mathbf{n = 3 0 )}\end{array}$ & $\begin{array}{c}\text { Conventional care } \\
(\mathbf{n}=\mathbf{3 2})\end{array}$ & p Value \\
\hline Vaginitis & $4(13.3 \%)$ & $2(6.25 \%)$ \\
\hline Wound infection & $1(3.3 \%)$ & $4(12.5 \%)$ \\
\hline Chest pain, no infarction & $2(6.6 \%)$ & $3(9.38 \%)$ \\
\hline Non-specific abdominal pain & 0 & $2(6.25 \%)$ & 0.193 \\
\hline Perioperative bleeding & $2(6.6 \%)$ & 0 \\
\hline Sub-ileus & 0 & $1(3.13 \%)$ \\
\hline Total number of patients with any complication & $9(30 \%)$ & $12(37.5 \%)$ & 0.112 \\
\hline Readmission to ER & $1(3.3 \%)$ & $11(34.4 \%)$ & 0.002 \\
\hline
\end{tabular}

ERAS - enhanced recovery after surgery; ER — emergency room

patients in the Conventional Group required hospital readmission after discharge. Both groups differ significantly in terms of readmission $(p=0.002)$.

In the ERAS group, one patient admitted to ER due to wound infection. In the Conventional Care group 4 patients admitted due to wound infection, 3 patients due to chest pain, 2 patients due to abdominal pain, one patient due to subileus and one patient due to severe candidal vaginitis.

\section{DISCUSSION}

Herein, we aimed to compare the postoperative compliance and complications between ERAS and conventional postoperative care in patients undergoing abdominal hysterectomies and revealed that introducing the ERAS protocol led to a significantly shorter length of hospital stay in hysterectomy patients, without any signs of increasing complications.

During surgery, the patients should be given optimal amounts of liquids (colloids, and crystalloids) while monitoring their cardiac functions. With appropriate intraoperative management of intravenous fluid administration, shortening of hospital stay, and recovery of gastrointestinal functions within a short time are aimed [14]. After the operation, intravenous fluids should be stopped, as early as possible, and oral intake should be initiated at the earliest time [15]. Oral nutrition within a short time after surgery, has been reported to decrease postoperative complications, mortality, and hospital stay [16]. The patients should be encouraged to start on the oral intake of clear fluids, and normal diet following surgery [15]. Oral fluid intake was started immediately after (Huibers et al,) 6. (Ren et al.), 12. (Moral et al.) hours or the day after (Shida et al.) the surgery by various authors as indicated [17-20]. In the present study, peri- and post-operative administrated intravenous fluids were significantly lower in the ERAS group.

Mobilization of the patients as early as possible is an important component of ERAS protocol. As it is known, early ambulation shortens hospital stay with resultant early discharge, decrease in postoperative complications, and hospital expenses, increase in patient's comfort, and early return to daily living activities leading to rapid recovery. In a study longevity of hospital stays was indicated as 5.7 days in early mobilized patients, while 12.9 days among mobilized patients in a long term [21]. Still in another study, it was stated that when early mobilization program which is a component of ERAS protocol was applied for patients who had undergone colorectal surgery on the day of operation, then morbidity, and hospitalization period decreased in these patients [22] In the present study, post-operative early mobilization on the first postoperative day was achi eved in eight (26.7\%) patients in the ERAS group. On the other hand, none of the control group patients mobilized on day 1 .

Many studies have demonstrated that implementation of ERAS protocol ensured fast-track postoperative recovery, and shortened hospital stay [10-13]. In a study by Carter et al. on 72 patients who had undergone laparotomy, the researchers observed that application of ERAS protocol enabled discharge within a short time [23]. Still, the same author performed a study on 389 patients who had undergone laparotomy with the indication of gynecologic cancer and indicated that though elder people had generally lower ASA scores, their operative times, and blood loss relatively decreased. Although their hospital stays had been longer when compared with younger patients, their complication rates had not increased [24]. Çağlı et al. performed a study on 100 patients aged $>65$ years who had undergone coronary artery surgery, and observed significantly shorter intensive care unit stay, and decreased time interval to their discharge in patients who were under ERAS protocol [25]. According to Relph et al. postoperative hospital stays after vaginal hysterectomy was an average of 42.9 hours in patients who received conventional postoperative care, and 23.5 hours in patients who were treated with ERAS protocol [26]. In the present study, ERAS protocol led to a significantly shorter length of hospital stay. 
In the literature, it has been indicated that complications developed in $5-40 \%$ of the patients followed up using ERAS protocol, while in $9.5-60 \%$ of the patients receiving conventional health care [10-13]. Relph et al. investigated 90 patients who underwent vaginal hysterectomy, and revealed that $15.6 \%$ of these patients who received conventional health care had applied to the emergency service after their discharge, while none of the patients in the group which received ERAS protocol had applied to the emergency service [26]. In the present study, although there were no significant differences in complications, readmission rates differed significantly. One patient in the ERAS Group and 11 patients in the Conventional Group required hospital readmission after discharge.

The common outcome derived from the results of many literature studies is that in addition to all contributions of ERAS protocol, it does not change the postoperative mortality rates and duration of rehospitalization [26-31]. However, since it requires a robust team work its implementation in every institute or unit is not easy [32]. Indeed, in a study by Jimenes et al., the authors indicated that adherence to ERAS protocol was a very slow process, and it was not practised at an anticipated level [2].

There is also a limitation to our study. It was not possible to perform a blinded study, because it is impossible to blind elements of care such as mobilization, information, fluids given, etc.

\section{CONCLUSIONS}

The ERAS protocol seems to be a simple tool for reducing the incidence of postoperative complications and shortening hospitalization. Further studies regarding ERAS and fast track protocols are needed, focusing on evaluations of more patient-related outcomes, such as patients' experience of the process, quality of life aspects and long-term consequences. There is also a need for international consensus and guidelines to standardize registration to make valid comparisons as a foundation for further improvement of the care of patients undergoing major gynecological surgery.

\section{Acknowledgements}

The authors are grateful to Ziya Salihoglu, Abdurrahim Derbent and Aytul Corbacioglu Esmer for providing helpful suggestions and linguistic modification.

\section{Ethics approval and consent to participate}

The Ethics Committee of Istanbul University of Health Sciences, Faculty of Medicine, Kanuni Sultan Suleyman Hospital approved this study. Reference No: KAEK/2016.12.12.

\section{Funding statement}

No financial support or funding was received for this paper.

\section{REFERENCES}

1. Abdikarim I, Cao XY, Li SZ, et al. Enhanced recovery after surgery with laparoscopic radical gastrectomy for stomach carcinomas. World J Gastroenterol. 2015; 21(47): 13339-13344, doi: 10.3748/wjg.v21.i47.13339, indexed in Pubmed: 26715818.

2. Khan JS. ERAS (Enhanced Recovery after Surgery) in Colorectal Surgery. In: Jimenez RS, Alvarez AB, Lopez JT, Jimenez AS, Conde FG, Saez JA. ed. Colorectal Cancer - Surgery, Diagnostics and Treatment. 2014.

3. Miller TE, Thacker JK, White WD, et al. Enhanced Recovery Study Group. Reduced length of hospital stay in colorectal surgery after implementation of an enhanced recovery protocol. Anesth Analg. 2014; 118(5): 1052-1061, doi: 10.1213/ANE.0000000000000206, indexed in Pubmed: 24781574.

4. Neville A, Lee L, Antonescu I, et al. Systematic review of outcomes used to evaluate enhanced recovery after surgery. Br J Surg. 2014; 101(3): 159-170, doi: 10.1002/bjs.9324, indexed in Pubmed: 24469616.

5. Hübner $M$, Addor V, Slieker J, et al. The impact of an enhanced recovery pathway on nursing workload: A retrospective cohort study. Int J Surg. 2015; 24(Pt A): 45-50, doi: 10.1016/j.ijsu.2015.10.025, indexed in Pubmed: 26523495.

6. Kehlet $\mathrm{H}$, Wilmore DW. Evidence-based surgical care and the evolution of fast-track surgery. Ann Surg. 2008; 248(2): 189-198, doi: 10.1097/SLA .0b013e31817f2c1a, indexed in Pubmed: 18650627.

7. Galaal K, Bryant A, Fisher AD, et al. Laparoscopy versus laparotomy for the management of early stage endometrial cancer. Cochrane Database Syst Rev. 2012(9): CD006655, doi: 10.1002/14651858.CD006655.pub2, indexed in Pubmed: 22972096.

8. Aarts JWM, Nieboer TE, Johnson N, et al. Surgical approach to hysterectomy for benign gynaecological disease. Cochrane Database Syst Rev. 2009(3): CD003677, doi: 10.1002/14651858.CD003677.pub4, indexed in Pubmed: 19588344.

9. Hansen $C T$, Sørensen $M$, Møller $C$, et al. Fast track hysterectomy. Eur J Obstet Gynecol Reprod Biol. 2001; 98(1): 18-22, indexed in Pubmed: 11516794.

10. Borendal Wodlin N, Nilsson L, Kjølhede P, et al. GASPI study group. The impact of mode of anaesthesia on postoperative recovery from fast-track abdominal hysterectomy: a randomised clinical trial. BJOG. 2011; 118(3): 299-308, doi: 10.1111/j.1471-0528.2010.02697.x, indexed in Pubmed: 20840529.

11. Carter J. Fast-track surgery in gynaecology and gynaecologic oncology: a review of a rolling clinical audit. ISRN Surg. 2012; 2012: 368014, doi: 10.5402/2012/368014, indexed in Pubmed: 23320193.

12. Pather S, Loadsman JA, Mansfield C, et al. Perioperative outcomes after total laparoscopic hysterectomy compared with fast-track open hysterectomy - a retrospective case-control study. Aust N Z J Obstet Gynaecol. 2011;51(5):393-396, doi: 10.1111/j.1479-828X.2011.01340.x, indexed in Pubmed: 21810085.

13. Kalogera E, Bakkum-Gamez JN, Jankowski CJ, et al. Enhanced recovery in gynecologic surgery. Obstet Gynecol. 2013; $122(2$ Pt 1): 319-328, doi: 10.1097/AOG.0b013e31829aa780, indexed in Pubmed: 23969801.

14. Magee $G$, Zbrozek A. Fluid overload is associated with increases in length of stay and hospital costs: pooled analysis of data from more than 600 US hospitals. Clinicoecon Outcomes Res. 2013; 5: 289-296, doi: 10.2147/CEOR.S45873, indexed in Pubmed: 23836999.

15. Gustafsson UO, Scott MJ, Schwenk W, et al. Enhanced Recovery After Surgery Society, Enhanced Recovery After Surgery (ERAS) Society, for Perioperative Care, European Society for Clinical Nutrition and Metabolism (ESPEN), International Association for Surgical Metabolism and Nutrition (IASMEN). Guidelines for perioperative care in elective colonic surgery: Enhanced Recovery After Surgery $\left(\operatorname{ERAS}\left({ }^{\oplus}\right)\right)$ Society recommendations. World J Surg. 2013; 37(2): 259-284, doi: 10.1007/s00268-0121772-0, indexed in Pubmed: 23052794.

16. Lewis SJ, Andersen HK, Thomas S. Early enteral nutrition within $24 \mathrm{~h}$ of intestinal surgery versus later commencement of feeding: a systematic review and meta-analysis. J Gastrointest Surg. 2009; 13(3):569-575, doi: 10.1007/s11605-008-0592-x, indexed in Pubmed: 18629592.

17. Huibers CJA, de Roos MAJ, Ong KH. The effect of the introduction of the ERAS protocol in laparoscopic total mesorectal excision for rectal cancer. Int J Colorectal Dis. 2012; 27(6): 751-757, doi: 10.1007/s00384011-1385-3, indexed in Pubmed: 22173714.

18. Ren Li, Zhu D, Wei Ye, et al. Enhanced Recovery After Surgery (ERAS) program attenuates stress and accelerates recovery in patients after radical resection for colorectal cancer: a prospective randomized controlled trial. World J Surg. 2012; 36(2): 407-414, doi: 10.1007/s00268-011-1348-4, indexed in Pubmed: 22102090. 
19. Alcántara-Moral M, Serra-Aracil X, Gil-Egea MJ, et al. E.B.S.Q.-C on behalf of the collaborative Group of Coloproctology Section of The Spanish Association of Surgeons. Observational cross-sectional study of compliance with the fast track protocol in elective surgery for colon cancer in Spain. Int J Colorectal Dis. 2014; 29(4): 477-483, doi: 10.1007/s00384013-1825-3, indexed in Pubmed: 24435243.

20. Shida $D$, Tagawa $K$, Inada $K$, et al. Enhanced recovery after surgery (ERAS) protocols for colorectal cancer in Japan. BMC Surg. 2015; 15: 90, doi: 10.1186/s12893-015-0079-0, indexed in Pubmed: 26215107.

21. McWilliams DJ, Pantelides KP. Does physiotherapy led early mobilisation affect length of stay on ICU? ACPRC Journal. 2008; 40: 5-11.

22. Teeuwen PHE, Bleichrodt RP, Strik C, et al. Enhanced recovery after surgery (ERAS) versus conventional postoperative care in colorectal surgery. J Gastrointest Surg. 2010; 14(1): 88-95, doi: 10.1007/s11605-009-1037-x, indexed in Pubmed: 19779947.

23. Carter J, Szabo R, Sim WW, et al. Fast track surgery: a clinical audit. Aust N Z J Obstet Gynaecol. 2010; 50(2): 159-163, doi: 10.1111/j.1479-828X.2009.01134.X, indexed in Pubmed: 20522073.

24. Carter J. Fast-track surgery in gynaecology and gynaecologic oncology: a review of a rolling clinical audit. ISRN Surg. 2012; 2012: 368014, doi: 10.5402/2012/368014, indexed in Pubmed: 23320193.

25. Cağli K, Uncu H, Işcan Z, et al. [The efficiency of fast track protocol in elderly patients who underwent coronary artery surgery]. Anadolu Kardiyol Derg. 2003; 3(1): 8-12, AXVII, indexed in Pubmed: 12626303.

26. Relph S, Bell A, Sivashanmugarajan V, et al. Cost effectiveness of enhanced recovery after surgery programme for vaginal hysterectomy: a comparison of pre and post-implementation expenditures. Int J Health
Plann Manage. 2014; 29(4): 399-406, doi: 10.1002/hpm.2182, indexed in Pubmed: 23661616.

27. Coolsen MME, van Dam RM, van der Wilt AA, et al. Systematic review and meta-analysis of enhanced recovery after pancreatic surgery with particular emphasis on pancreaticoduodenectomies. World J Surg. 2013; 37(8): 1909-1918, doi: 10.1007/s00268-013-2044-3, indexed in Pubmed: 23568250.

28. Lemanu DP, Singh PP, Stowers MDJ, et al. A systematic review to assess cost effectiveness of enhanced recovery after surgery programmes in colorectal surgery. Colorectal Dis. 2014; 16(5): 338-346, doi: 10.1111/codi.12505, indexed in Pubmed: 24283942.

29. Wang LH, Fang F, Lu CM, et al. Safety of fast-track rehabilitation after gastrointestinal surgery: systematic review and meta-analysis. World J Gastroenterol. 2014; 20(41): 15423-15439, doi: 10.3748/wjg.v20. i41.15423, indexed in Pubmed: 25386092.

30. Yin X, Zhao Y, Zhu X. Comparison of fast track protocol and standard care in patients undergoing elective open colorectal resection: a meta-analysis update. Appl Nurs Res. 2014; 27(4): e20-e26, doi: 10.1016/j. apnr.2014.07.004, indexed in Pubmed: 25176108.

31. Yu Z, Zhuang CL, Ye XZ, et al. Fast-track surgery in gastrectomy for gastric cancer: a systematic review and meta-analysis. Langenbecks Arch Surg. 2014; 399(1): 85-92, doi: 10.1007/s00423-013-1148-4, indexed in Pubmed: 24337792

32. Agrafiotis AC, Corbeau M, Buggenhout A, et al. Enhanced recovery after elective colorectal resection outside a strict fast-track protocol. A single centre experience. Int J Colorectal Dis. 2014; 29(1): 99-104, doi: 10.1007/s00384-013-1767-9, indexed in Pubmed: 23982426. 